\title{
Vitamin D deficiency and diseases: a review from Pakistan
}

\author{
Yasir Mahmood ${ }^{1}$, Nazish Waris ${ }^{2}$, Asher Fawwad ${ }^{2}$, and Abdul Basit ${ }^{2}$ \\ ${ }^{1}$ University of Karachi \\ ${ }^{2}$ Baqai Medical University
}

July 28, 2020

\begin{abstract}
Objective: Vitamin D deficiency is claimed to be associated with many diseases in the world populations. Many studies reported that vitamin D deficiency is quite prevalent in Pakistan. The aim of this review is to describe the current status of vitamin D deficiency in healthy individuals and in different disease conditions in this country. Methods: Search engines such as "Google Scholar", "Medline and PubMed" were used by applying key words such as vitamin D deficiency, vitamin D deficiency and different disease conditions in Pakistani population. Results: Total 82 studies were included in which 12 studies showed vitamin levels less than $30 \mathrm{ng} / \mathrm{mL}$ in the healthy individuals (male and female) and 70 studies in different disease conditions. It found that about $64.6 \%$ healthy subjects had vitamin D levels less than $30 \mathrm{ng} / \mathrm{mL}$. Moreover, 70 studies showed its deficiency in some diseases such as musculoskeletal, bone and periodontal problems, nursing mothers and children, tuberculosis, diabetes, cardiovascular problems and some type of cancers. Conclusion: The current status of vitamin D deficiency in healthy population and in several diseases and conditions are thoroughly discussed in this review. This review could be helpful to understand status of vitamin D and different aspects of vitamin D research in this population
\end{abstract}

Title: Vitamin D deficiency and diseases: a review from Pakistan

Running Title: Vitamin D deficiency: a review from Pakistan

Author List

Yasir Mahmood, PhD

Senior Research Associate

Research Department

Baqai Institute of Diabetology and Endocrinology

Baqai Medical University, Karachi-Pakistan

Email: ymahmood@bide.edu.pk

Nazish Waris, M.Phil.

Ph.D. Scholar

Clinical Biochemistry and Psychopharmacology Research Unit

Department of Biochemistry, University of Karachi-Pakistan

Research Associate,

Baqai Institute of Diabetology and Endocrinology,

Baqai Medical University, Karachi-Pakistan. 
Email: nwaris@bide.edu.pk

\section{Asher Fawwad, Ph.D.}

Professor \& Head of the Biochemistry Department

Baqai Medical University

Research Director (Honorary)

Department of Research

Baqai Institute of Diabetology and Endocrinology,

Baqai Medical University, Karachi-Pakistan.

Email: asherfawwad@bide.edu.pk

\section{Abdul Basit, FRCP}

Professor of Medicine

Baqai Medical University

Director

Baqai Institute of Diabetology and Endocrinology

Baqai Medical University, Karachi-Pakistan

Email: abdulbasit@bide.edu.pk

\section{Author for Correspondence}

\section{Asher Fawwad, Ph.D.}

Professor \& Head of the Biochemistry Department

Baqai Medical University

Research Director (Honorary)

Department of Research

Baqai Institute of Diabetology and Endocrinology,

Baqai Medical University, Karachi-Pakistan.

Email: asherfawwad@bide.edu.pk

Total Pages: 40

Words Count: 4,520

Tables: 2

Figures: 00

References: 136

Author contributions:

Yasir Mahmood: Wrote the manuscript, literature review, analysis and drafting.

Nazish Waris: Wrote the manuscript, literature review, analysis and drafting.

Asher Fawwad: Edit and approved the manuscript 
Abdul Basit: Edit and approved the manuscript

Conflict-of-interest statement: No potential conflicts of interest. No financial support has been taken from any funding agency.

\section{Abstract \\ Objective:}

Vitamin D deficiency is claimed to be associated with many diseases in the world populations. Many studies reported that vitamin D deficiency is quite prevalent in Pakistan. The aim of this review is to describe the current status of vitamin D deficiency in healthy individuals and in different disease conditions in this country.

\section{Methods:}

Search engines such as "Google Scholar", "Medline and PubMed" were used by applying key words such as vitamin D deficiency, vitamin D deficiency and different disease conditions in Pakistani population.

\section{Results:}

Total 82 studies were included in which 12 studies showed vitamin levels less than $30 \mathrm{ng} / \mathrm{mL}$ in the healthy individuals (male and female) and 70 studies in different disease conditions. It found that about $64.6 \%$ healthy subjects had vitamin D levels less than $30 \mathrm{ng} / \mathrm{mL}$. Moreover, 70 studies showed its deficiency in some diseases such as musculoskeletal, bone and periodontal problems, nursing mothers and children, tuberculosis, diabetes, cardiovascular problems and some type of cancers.

\section{Conclusion:}

The current status of vitamin D deficiency in healthy population and in several diseases and conditions are thoroughly discussed in this review. This review could be helpful to understand status of vitamin D and different aspects of vitamin D research in this population.

Key words: Vitamin D, Vitamin D deficiency, Diseases, Pakistani population, Pakistan

\section{How did you gather the information you considered in your review?}

The information present in this review article is gathered from online data sources such as "Google Scholar", Medline and PubMed".

\section{What is the 'take-home' message for the clinician?}

The vitamin D deficiency is quite prevalent in Pakistani population and could affect different diseases. Therefore, it is worthwhile to consider the vitamin D levels in the management of such disease conditions which are described in this article.

\section{Introduction:}

Vitamin D is an essential micro nutrient for wellbeing of a living individual (1). Sunlight plays an important role in its production in the body (1). It works as a pleiotropic hormone (2). Its deficiency in children is manifested by improper growth of bone commonly known as rickets (3). Previously, vitamin D was considered to only affect bone metabolism and calcium absorption, but later studies found its vital role in many other physiological functions in the body (4). It was found that almost all cell types exhibit vitamin $\mathrm{D}$ receptors (VDR) and all vital organs and tissues of the body are benefitted by vitamin D (5). Since past decades, much attention have been diverted to understand its role in different modalities such as diabetes mellitus, cardiovascular disorders, infections especially tuberculosis and some auto-immune disorders such as psoriasis and multiple sclerosis etc (5). Even some types of cancers such as prostate, breast and colon have been correlated with its deficiency $(6,7)$. 
As Pakistan is a developing country and most of its population resides in the villages (8). Its geographical location $\left(30.3753^{\circ} \mathrm{N}, 69.3451^{\circ} \mathrm{E}\right)$ makes it a country of proper sun light throughout the year (9). Due to the cultural norms, people wear dresses that cover the whole body. (10). Malnourishment in the villages and imbalanced diet in the urban settings are common problems in this population (11). Due to un-awareness and cultural norms, people could not get proper sun shine, therefore vitamin D deficiency is prevalent in all over the country (13).

This review would be helpful to understand the recent status of vitamin D deficiency in the healthy subjects and in different diseases and conditions in the Pakistani population.

\section{Literature search:}

The search engines such as "Google Scholar", "Medline and PubMed" were used by applying some search key terms; "Vitamin D Pakistan", "Vitamin D diseases Pakistan", "Vitamin D deficiency Pakistan", "Vitamin D tuberculosis Pakistan", "Vitamin D Children Pakistan", "Vitamin D rickets Pakistan", Vitamin D Women Pakistan", "Vitamin D Cancer Pakistan" and "Vitamin D receptor SNPs Pakistan".

\section{Inclusion and exclusion criteria:}

All relevant studies found by above mentioned research terms were included. However, those studies were excluded which were conducted in Pakistani communities residing outside the country.

\section{Status of vitamin D deficiency in healthy individuals:}

The results of a small-scale survey in a randomly selected asymptomatic subjects $(n=300)$ of Karachi showed that $84.3 \%$ subjects had vitamin D levels less than $30 \mathrm{ng} / \mathrm{mL}$ (14). Female subjects (62.3\%) were found more vitamin D deficient as compared to male subjects (55.2\%). Another study in 858 subjects (351 males and 507 females) belonged to low income peri-urban community in Karachi (15) showed that $89.9 \%$ subjects had vitamin D levels less than $30 \mathrm{ng} / \mathrm{mL}$. Female subjects were again found more vitamin D deficient than male subjects.

A study conducted in 500 subjects (29\% males and $71 \%$ females) from the capital city Islamabad (13) showed that only $11 \%$ subjects had normal vitamin D levels $(30 \mathrm{ng} / \mathrm{mL})$.

An interesting study was conducted in the undergraduate medical students of different universities and health professionals to analyze the awareness about sunlight exposure and importance of vitamin $\mathrm{D}$ and the symptoms associated with its deficiency such as muscular pain and fatigue (16). The result of this study revealed that the participants were well aware about importance of vitamin D and the sign of its deficiency but most of the participants were found to avoid sun exposure intentionally, and only $8 \%$ of the participants knew about minimum sun light exposure to prepare vitamin D. Vitamin D levels were not measured in this study therefore it was difficult to correlate the symptoms such as body pain with vitamin D deficiency.

A similar study was conducted to analyze vitamin D levels in the students of a medical college of Peshawar which showed that $95.19 \%$ subjects had vitamin D deficiency. (17)

Another study was conducted to evaluate vitamin D status in 191 randomly selected medical students ( $86.43 \%$ females and $13.57 \%$ males) in Karachi which revealed that $96.4 \%$ students had low vitamin D levels $(<30 \mathrm{ng} / \mathrm{mL}) \cdot(18)$

A comprehensive study was conducted in healthy subjects (50 males and 38 females) of Lahore (19). The results showed that the average vitamin D in the $98.86 \%$ subjects was below $30 \mathrm{ng} / \mathrm{mL}$. Subjects such as females, physically less active persons, indoor job holders, people with high socioeconomic status along with higher education and subjects having fair skin complexion were found more vitamin D deficienct.

Another small-scale study was conducted in 244 (79\% females and $21 \%$ males) healthy adults (20). Vitamin D deficiency $(<30 \mathrm{ng} / \mathrm{mL})$ was present in $76.2 \%$ subjects and showed significant correlation with the area of skin exposed to sunlight. 
An observational study to assess the prevalence of vitamin $\mathrm{D}$ deficiency in healthy male subjects $(\mathrm{n}=180)$ was conducted in Hyderabad, Sindh (21). It found that $88.8 \%$ subjects had vitamin D deficiency $(<30 \mathrm{ng} / \mathrm{mL})$.

A large study was conducted to evaluate the effect of socio-economic conditions, different types of residencies and vitamin D levels in different localities of Karachi (22). A total of 4788 subjects were randomly selected. Results showed that $74 \%$ of the subjects had vitamin D deficiency $(<30 \mathrm{ng} / \mathrm{mL})$. Post hoc analyses revealed that subjects belonged to densely populated areas with low socio-economic status had significantly lower levels of vitamin D as compared with subjects of middle income and resident of less densely populated areas.

A study to evaluate the vitamin D levels in 305 premenopausal women in different parts of Karachi (23) revealed that $90.1 \%$ subjects had vitamin D deficiency $(<30 \mathrm{ng} / \mathrm{mL})$. The vitamin D levels were found to be associated with low sun exposure.

A large retrospective data analysis (audit) of 60937 specimens ( $30.7 \%$ male and $69.3 \%$ female) from all over the country revealed that $61.1 \%$ subject had mean $\log$ vitamin $\mathrm{D}$ value as $1.14 \mathrm{ng} / \mathrm{mL}(13.8 \mathrm{ng} / \mathrm{mL})$. The specimen received from Khyber Pakhtunkhwa had lowest levels $(11 \mathrm{ng} / \mathrm{mL})$ and the specimen received from Azad Kashmir had highest levels of vitamin D $(17.1 \mathrm{ng} / \mathrm{mL})$. Overall results showed prevalence of vitamin $\mathrm{D}$ deficiency in all over the country regardless location and gender differences (24).

Another study conducted to assess the vitamin D status in different parts of the country revealed that only $15.3 \%$ of 4830 subjects had normal vitamin D levels (25).

\section{Vitamin d deficiency in different disease conditions:}

\section{Musculoskeletal, Bone and Periodontal Health}

Vitamin D deficiency is directly associated with some bones and musculoskeletal problems such as rickets, osteopenia, osteomalacia, osteoporosis and osteoarthritis (26). Vitamin D supplementation showed beneficial effects in Musculoskeletal pain proving it to be a sign of Vitamin D deficiency $(27,28)$. A study conducted in 400 participants with complain of musculoskeletal pain ( $43.5 \%$ males and $55.5 \%$ females) with age ranging from 18 to 80 years in a less developed city Swat (29) which showed only $7 \%$ of the subjects had adequate levels of vitamin $\mathrm{D}(>30 \mathrm{ng} / \mathrm{mL})$. Similar results were obtained from a cross-sectional observational study conducted in an outpatient department of Rahim Yar Khan, Punjab (30). About 400 patients with musculoskeletal pain showed that $47 \%$ of the subjects had low vitamin D levels $(<30 \mathrm{ng} / \mathrm{mL})$. In another study, fibromyalgia and nonspecific musculoskeletal pain were reported with lower levels of vitamin D in female subjects in Karachi (31). Similarly, out of 100 subjects with sign of fatigue, 92 subjects were also found vitamin D deficienct (32).

Vitamin D deficiency with poor bone health was observed in premenopausal women (33). It was found that out of 174 subjects, the high bone turnover was present in $36.8 \%$ subjects and vitamin D deficiency was observed in $96.9 \%$ subjects. A similar study was conducted in 143 postmenopausal women in rural communities to assess bone mineral density by quantitative ultrasound index (QUI) and their dietary habits (34). The results showed that $42 \%$ of the women had osteopenia and $29 \%$ had an indicative score of osteoporosis. Vitamin D deficiency and low calcium intake in the diet were found more prevalent in this study.

Another study conducted to assess dietary calcium, vitamin D status and bone turnover in 305 women subjects in three towns of Karachi city (35). Overall, $90.5 \%$ subjects were found vitamin D deficient and in these, $42.6 \%$ subjects had secondary hyperparathyroidism. The $76.7 \%$ female subjects had low while, only $23.3 \%$ had normal bone turnover.

A survey was conducted to assess the status of calcium and vitamin D deficiency along with awareness about osteopenia and osteoporosis in 252 female subjects in Karachi out of which only $34 \%$ subjects had its awareness while $77 \%$ subjects had pain in back, legs and joints. (36)

A multicentric cross-sectional study including 291 subjects (39.5\% males and $60.5 \%$ females) from three big cities (Karachi, Lahore and Islamabad) was conducted (37). Overall $84 \%$ subjects had vitamin D levels below the normal limit $(30 \mathrm{ng} / \mathrm{mL})$. A significant difference in Vitamin D levels was found on the basis of age and 
skin color. Total $147(48 \%)$ subjects had low BMD and out of them 98 (66.6\%) had osteopenia. In these total 98 osteopenic subjects, $80(81.6 \%)$ had low vitamin D levels. The vitamin D levels were not significantly different between subjects having low bone mineral density, serum calcium and phosphorus levels.

The association of periodontal health with vitamin D deficiency is quite prevalent worldwide (38). A study conducted in pregnant $(n=36)$ and non-pregnant women $(n=35)$ revealed that pregnant women were more vitamin $\mathrm{D}$ deficient than non-pregnant women but no association between vitamin $\mathrm{D}$ deficiency and periodontal diseases was found (39). The results of a randomized clinical trial conducted in 85 female of 12 weeks of gestation revealed that after $4000 \mathrm{IU}$ dose of vitamin $\mathrm{D}$ on daily basis could not improve the periodontal status and birth weight among the study subjects (40).

The association of vitamin $\mathrm{D}$ level with above mentioned disease conditions was not described on the basis of adequately adjusted model, therefore it could not be inferred that only vitamin D deficiency is responsible for above mentioned conditions.

\section{Nursing mothers and children:}

Vitamin D deficiency has also been associated with some complications such as poor fetal growth, rickets and neonatal eczema (41). Vitamin D status was assessed in parturient and gravidae in a tertiary care hospital in Karachi (42). Maternal and fetal vitamin D levels were estimated from blood and cord blood respectively. It found that $89 \%$ of the subjects were vitamin D deficient $(<30 \mathrm{ng} / \mathrm{mL})$ and vitamin D levels were found inversely correlated with maternal blood pressure.

Vitamin D deficiency was also found in the nursing mothers (85.1\%) of South Punjab (43). According to the study, most of the mothers used to live in open houses with maximum chances of sun exposure (168.81 minutes/day). Despite of ample sun exposure, the reason of vitamin D deficiency could be clothing style of the females that is very common in the society.

Vitamin D deficiency was also found in healthy infants from 9 to 12 months of age in Rawalpindi (44). The radiological studies of wrists showed that $53.8 \%$ of infants had rickets with sub-optimal levels of vitamin D $(<30 \mathrm{ng} / \mathrm{mL})$.

The possible reasons of the vitamin D deficiency in pregnant women could be low sun exposure and less physical activity during pregnancy. Clothing style and cultural regulations (not to go outside during pregnancy), may play their role in this condition.

Another study revealed that $99.5 \%$ women and $97.3 \%$ neonates in Karachi while, $89 \%$ of women and $85 \%$ of neonates in rural areas of district Jehlum were found vitamin D deficient. (45) Similarly, another study revealed maternal vitamin D deficiency $(<30 \mathrm{ng} / \mathrm{mL})$ during early pregnancy in $44 \%$ (out of 301 ) of the subjects visiting a tertiary care hospital in Karachi (46). A similar study reported $77 \%$ vitamin D deficiency from neonates to children (15 year of age) (47).

Nutritional rickets was observed in $74 \%$ children admitted in a health care center in Karachi with the symptoms of severe pneumonia (4). The rickets was more prevalent (79.8\%) in age group between 2 to 12 months. Vitamin D status was not measured in this study, but it could be inferred that the children would have severe vitamin D deficiency.

Sub-clinical rickets was also observed in several areas of Pakistan. A study conducted in 189 children with 11 to 16 years of age showed $27 \%$ prevalence of sub-clinical rickets in Hazara district, KPK (48). Similarly in Kaghan Valley, 26 students were evaluated for sub-clinical rickets and all were found to have this condition along with vitamin D deficiency and high alkaline phosphatase levels (49).

An interventional study was conducted to evaluate the effect of two oral doses of 200000 IU of vitamin D in the malnourished children of 6 to 58 months age range (50). The results of this interventional clinical study showed significant improvements in the developmental indices in these children as compared with control group. 


\section{Diabetes mellitus:}

Vitamin D deficiency has been observed in the onset of diabetes (type 1 and 2) in world populations (51). The active form of vitamin D (calcitriol) after binding with its receptor (VDR) plays an important role in insulin secretion and the insulin sensitivity in the targeted cells (52).

Some observational studies in Pakistani population showed vitamin D deficiency in type 2 diabetic subjects $(53,54)$. A case control study conducted in a district headquarter hospital Gujranwala, Punjab found that vitamin $\mathrm{D}$ levels were significantly lesser in diabetic patients as compared with control group but both groups had vitamin D levels less than $20 \mathrm{ng} / \mathrm{mL}$ (55). In another study, vitamin D levels were found negatively associated with blood glucose levels of type 2 diabetic patients in Karachi (56). Similarly, another study showed that $62 \%$ of type 2 diabetic patients had elevated levels of HbA1c and poor glycemic control along with vitamin D deficiency (57). A study was conducted by our group found that vitamin D levels were negatively correlated with random blood sugar and HbA1c levels in the diabetic patients. However, vitamin D levels were not significantly different between good and poor glycemic control subjects (58).

Elevated levels of HbA1c represent poor glycemic control and it is a common modality in type 2 diabetic patients (59). A study showed positive association of vitamin D deficiency with poor glycemic control in Pakistani population (60).

A randomized clinical trial was conducted to evaluate the effects of vitamin D administration to improve glycemic control in type 2 diabetic patients at a tertiary care hospital in Lahore, Punjab (61). Patients were divided in to two groups. One group was administered only Metformin $500 \mathrm{mg}$ after dinner while, second group was administered 200,000 IU of vitamin D along with $500 \mathrm{mg}$ Metformin after dinner for six months of period. The result showed improvement in vitamin D levels in the group administered with vitamin D and metformin, but HbA1c levels were not found significantly different after six months between two groups.

Vitamin D deficiency has also been studied with the relevance of dyslipidemia in type 2 diabetic patients (62). A study conducted to evaluate the role of statin use with vitamin D levels showed no significant association with dyslipidemia. But a significant negative association was found between total cholesterol and vitamin D levels suggesting an important impact of vitamin D levels with hypercholesterolemia in the type 2 diabetic patients (63).

Microvascular complications in diabetes such as retinopathy, neuropathy and nephropathy have been associated with vitamin D deficiency in world populations (64). The results of meta-analysis revealed that vitamin $\mathrm{D}$ deficiency is associated with the onset of diabetes neuropathy in Caucasians and Asian populations (65). Microvascular complications are prevalent in Pakistani population and Vitamin D deficiency was found to be associated with diabetic retinopathy in type 2 diabetic patients of Peshawar, KPK (66).

\section{Cardiovascular disorders:}

Vitamin D receptors and its metabolizing enzymes are present in the whole cardiovascular system (67). The VDR knock-out mice showed severe impairments in cardiovascular system including cardiac hypertrophy (68). Many observational studies and results of meta-analyses showed vitamin D deficiency is associated with the cardiovascular disorders $(69,70,71,72,73)$. The studies to probe the association of vitamin $\mathrm{D}$ deficiency with cardiovascular events in Pakistani population are very few. A study conducted in patients with first acute myocardial infarction (AMI) showed association between vitamin D deficiency and a genetic variant in the vitamin D binding protein with this event (74). However, another study conducted to evaluate the role of vitamin D and calcium deficiency with hypertension showed weak correlation of these two factors with mean, systolic and diastolic blood pressures (75).

Vitamin D deficiency was also studied with the relevance of cardio metabolic syndrome and found that it was significantly associated with hypertension in Pakistani population (76). High levels of parathyroid hormone (PTH) could be responsible for the development of hypertension $(77,78)$. One study conducted in Pakistani population showed that PTH levels were significantly associated with variation (R990G) of calcium sensing gene in the vitamin D deficient subjects (79). However, blood pressure was not monitored in this study. 


\section{Cancer:}

Many epidemiological studies showed higher prevalence of some type of cancers in those geographical locations which observe less sun exposure throughout the year (80). The $50 \mathrm{ng} / \mathrm{mL}$ and $30 \mathrm{ng} / \mathrm{mL}$ of vitamin D were found to be associated with $60 \%$ and $33 \%$ decreased risk of colorectal cancer, respectively, and more than $50 \mathrm{ng} / \mathrm{mL}$ of vitamin $\mathrm{D}$ was found to have preventive role (81). Other studies also showed that the UVB exposure and vitamin D are associated with lower cancer risk and higher survival from cancer (82).

In Pakistani population, several studies have been conducted to probe the link between vitamin D deficiencies with incidence of some cancers. Breast cancer is a common cancer type in the women of this country (83, 84). Studies conducted in different parts of this country showed negative association of vitamin D levels with breast cancer incidences. In one of the study, 42 newly diagnosed breast cancer subjects were found vitamin D deficient (85). In Lahore, 300 newly diagnosed pre and post-menopausal women belonging to different parts of the Punjab province showed positive association with vitamin D deficiency and the tumor size in breast cancer (86). However, tumor grade and stage were not associated with vitamin D levels in this study. A study conducted in 90 newly diagnosed breast cancer patients in Lahore showed association of breast cancer with low vitamin D levels (87). Another study to understand the onset of breast cancer in women with the relevance of dietary habits, dress style and sun exposure showed that vitamin D deficiency was more prevalent in breast cancer patients (88).

A study to assess the effect of vitamin D supplementation in breast cancer risk showed that the odds of breast cancer were more significant in the subjects which were not taking vitamin D supplement (89). A cross sectional study to evaluate BMI, bone markers and vitamin D status in the newly diagnosed breast cancer patients showed low levels of vitamin D in the subjects (90). Another study conducted in Multan, South Punjab also showed that $90 \%$ breast cancer patients had vitamin D deficiency (91).

Instead of breast cancer, vitamin D deficiency has been studied in leukemic patients. One study showed vitamin D deficiency was prevalent in patients of B-chronic lymphoid leukemia (92). Another study showed that after remission-induction chemotherapy, this deficiency was increased as compared with subjects with no chemotherapy (93).

\section{Tuberculosis:}

The first treatment of skin tuberculosis was discovered by lamp arc radiation and the inventor Neils Rayberg Finsen (1890-1904) was awarded by Noble prize for this discovery (94). It is suggested that UV radiation from lamp arc produces vitamin $\mathrm{D}$ in the body and facilitates the production of anti-microbial peptides such as cathelicidin to fight against infectious diseases including tuberculosis $(95,96,97)$. Many observational studies showed strong association of vitamin D deficiency with tuberculosis in different populations including Pakistani population $(98,99,100)$.

Some of the case control studies found severe vitamin D deficiency in patients with pulmonary and extra pulmonary tuberculosis $(98,101,102,103,104,105,106,107)$. A case control study designed to evaluate the amount of vitamin D, anti-microbial peptide cathelicidin, chemerin and inflammatory marker TNF $\alpha$ in pulmonary tuberculosis and healthy subjects found significant association was present between vitamin $\mathrm{D}$, cathelicidin, chemerin and TNF $\alpha$. (108).

An interventional trial named as SUCCINIT study (Supplementary cholecalciferol in recovery from tuberculosis) was conducted in patients with pulmonary tuberculosis to evaluate the effects of vitamin D supplementation (109). A total of 259 patients with newly diagnosed TB were randomly divided into two groups (Vitamin D group $\mathrm{n}=132$ and placebo group $\mathrm{n}=129$ ). The vitamin $\mathrm{D}$ group was administered by $600000 \mathrm{IU}$ of vitamin D on weekly basis for two weeks along with standard medications while, placebo group was administered by normal saline along with standard medications. The results of this study showed improvement in clinical, radiological and host defense outcomes in the patients of vitamin D group.

Another interventional trial was conducted to evaluate adjuvant effects of vitamin $\mathrm{D}$ with anti-tuberculosis therapy (ATT) as compared with ATT alone for 77 days (110). The results showed improvement in some 
parameters such as increase in serum vitamin D, calcium, BMI and hemoglobin and decrease in erythrocytes sedimentation rate (ESR), C-reactive proteins (CRP), total white blood count and a 12 days earlier sputum conversion as compared with placebo group.

A similar study also showed early sputum conversion in smear positive pulmonary tuberculosis by the administration of vitamin D (100000 IU) on every fourteenth day for three months (111). The results showed improvement in the vitamin D levels and rate of sputum smear conversion in patients with pulmonary tuberculosis.

CXCL10 is a chemo-attractant factor that is found to be elevated in TB patients (112). Vitamin D levels were found negatively associated with the CXCL10 levels in 119 TB patients in Karachi (113).

\section{Genetic studies:}

Genetic variations in the genes of vitamin D synthesis and its metabolism have been linked with many diseases in the world populations $(114,115,116)$.

Vitamin D receptor (VDR) is a type of nuclear receptor that after binding its ligand calcitriol (active form of vitamin D) regulates expression of many genes $(117,118)$. The variations in the VDR gene have been associated with several disease conditions in different populations $(119,120,121,122)$.

Many studies in Pakistani population showed the association of some diseases with certain types of SNPs in VDR gene. The Apa1 SNP present in the 3' intronic region of VDR may affects the stability of mRNA of VDR (123). Some SNPs in VDR gene were found to be associated with Type 1 diabetes (T1D) (124). Another study was conducted to probe a link between T1D and two SNPs of VDR (Fok1 and Apa1) in children (125). The results of this study showed vitamin D deficiency was prevalent in studied group but no significant association was found of any of these SNPs with T1D. It may be due to very small sample size (44 cases and 44 controls).

SNPs in VDR gene have been studied with the relevance of vitamin D levels in healthy women of Pakistani population (126). Two SNPs (Fok1 and Taq1) were found significantly associated with vitamin D deficiency and insufficiency.

Vitamin D circulates in the body after binding with vitamin D binding protein (VDBP); a type of transporter protein (127). A case control study showed significant association of group-specific 1-2 (Gc 1-2) genotype with the risk of T2DM in the subjects (128). Another study found a significant link between vitamin D deficiency and IF-IF genotype of VDBP gene with acute myocardial infarction (AMI) in Pakistani population (74). Breast cancer is quite prevalent in Pakistani women (83). The analyses of 360,933 breast cancer cases revealed that Asian Pakistani/Indian women had higher frequency of breast cancer than Caucasians (129). Meta analyses of some studies carried out to probe the role of variation in VDR gene with the onset of breast cancer, showed its positive correlation in different world populations (130). Many studies in Pakistani population revealed the association of variations in VDR gene with breast cancer. A case-control study (103 cases and 161 controls) showed the GG genotype of cdx-2 SNP may increase the risk of breast cancer in young females belonged to the Southern Punjab (131). The Tru9I SNP in VDR gene was studied in 228 patients and 503 controls and found that this SNP could be associated with the risk of this disease (132). It found from the same study that the mutant Tru9I was found significantly associated with grade IV carcinoma in the study group.

The $\mathrm{b}$ allele of Bsm1 polymorphism of VDR gene showed positive association with breast cancer (133). This study included 463 cases with known BRCA1/2 status and 1012 controls. Sub-group analysis of the study revealed that BRCA1/2 non-carriers and subjects with a family history of breast and/or ovarian cancer had significant association of this allele with this disease condition.

The overall results of many studies showed that the variations in VDR gene are not associated with some disease conditions in Pakistani population. The results of a study conducted by our group showed that only 
TT genotype of TaqI polymorphism was significantly associated with T2DM in Karachi, Pakistan (Mahmood et al., unpublished data).

\section{Summary:}

Total 82 studies were included in which 12 studies represented vitamin D levels in healthy individuals (Table 1) and 70 studies (Table 2) in different conditions. It found that vitamin D deficiency is prevalent in all parts of the country and about $64.6 \%$ healthy subjects had vitamin D levels less than $30 \mathrm{ng} / \mathrm{mL}$. Moreover, 70 studies showed its deficiency in some diseases such as musculoskeletal, bone and periodontal problems, nursing mothers and children, tuberculosis, diabetes, cardiovascular problems and some type of cancers.

Women were found more deficient than men due to the cultural norms and clothing style in this population. Some previous studies in different parts of the world also showed that cultural norms and dress style were associated with vitamin D deficiency in women (134-136).

Limited studies have been conducted to see the association of genetic variations with some diseases. The results of such studies could not establish any significant association with different diseases. This could be due to the small sample size with limited scope of the study.

\section{General recommendations:}

The vitamin D levels should be kept at normal range $(30 \mathrm{ng} / \mathrm{mL})$ either by vitamin $\mathrm{D}$ supplementation or by optimum sun exposure. Sun exposure should be preferred due to its benefits on other physiological functions.

Men, women and children should be encouraged and facilitated to expose themselves in the sun shine. Balanced diet containing dairy products fortified with vitamin $\mathrm{D}$ and the use of sea foods should be recommended for child bearing and nursing mothers.

A country wide survey could be conducted to assess the present status of vitamin D in this population and the possible reasons of its deficiency in this population.

\section{Limitations:}

Most of the studies did not use appropriate measure of analyses using adequately adjusted statistical models to associate vitamin $\mathrm{D}$ deficiency with the disease conditions alongwith different assay types which may affect the results of vitamin $\mathrm{D}$ levels.

The results of genetic studies are limited and not conclusive therefore further investigations with large data set are required to infer logical conclusions

\section{References:}

1. Pearce SH and Cheetham TD. Diagnosis and management of vitamin D deficiency. BMJ. 2010, 340:b5664.doi: 10.1136/bmj.b5664.

2. Verstuyf A, Carmeliet G, Bouillon R, Mathieu C.Vitamin D: a pleiotropic hormone.Kidney Int. 2010,78(2):140-145.

3. PettiforJM,Thandrayen K,Thacher TD.Vitamin D deficiency and nutritional rickets in children. In Vitamin D. 2018, 2:179-201. Academic Press.

4. Bouillon R, Marcocci C, Carmeliet G, Bikle D, White JH, Dawson-Hughes B, Lips P, Munns CF, LazarettiCastro M, Giustina A, Bilezikian J.Skeletal and extra-skeletal actions of vitamin D: current evidence and outstanding questions.Endocr.rev. 2018, 40(4):1109-1151. doi: 10.1210/er.2018-00126.

5. Haussler MR. Vitamin D receptors: nature and function.Ann. Rev.Nutr. 1986,6(1):527-562.

6. Grant WB.A Review of the Evidence Supporting the Vitamin D-Cancer Prevention Hypothesis in s2017.Anticancer Res. 2018,38(2):1121-1136. 
7. Pludowski P, Holick MF, Pilz S, Wagner CL, Hollis BW, Grant WB, Shoenfeld Y, Lerchbaum E, Llewellyn DJ, Kienreich K, Soni M.ludowski. Vitamin D effects on musculoskeletal health, immunity, autoimmunity, cardiovascular disease, cancer, fertility, pregnancy, dementia and mortality - a review of recent evidence.AutoimmunRev. 2013,12(10):976-989.

8. Cooper MA, Holle RL. How to Deliver the Message to Vulnerable Populations.In Reducing Lightning Injuries Worldwide. 2019, 211-220. Springer, Cham. https://doi.org/10.1007/978-3-319-77563-0_21.

9. BakhtiarF. and Ahmed A, A Review of Solar Energy in Pakistan: Current Status and Future Prospects.Science, Technology, and Development. 2017;36(3):189-95.

10. MalikIH.Culture and customs of Pakistan. 2006: Greenwood Publishing Group.

11. HussainA.The Nutrition emergency. 2017. https://www.thenews.com.pk/print/226262-The-nutritionemergency

12. Yu MG, Castillo-Carandang N, Sison ME, Uy AB, Villarante KL, Maningat P, Paz-Pacheco E, AbesamisCubillan E. Development and validation of a sunlight exposure questionnaire for urban adult Filipinos. Epidemiology and health. 2018,40.

13. Kiani RA. Prevalence of Vitamin-D Deficiency in Urban Population: A Retrospective Analysis.Ann. Pak. Inst. Med. Sci. 2015,11(2):90-94.

14. Sheikh A, Saeed Z, Jafri SA, Yazdani I, Hussain SA.Vitamin D levels in asymptomatic adults-a population survey in Karachi, Pakistan. PloS one, 2012. 7(3):e33452.

15. Mehboobali N, Iqbal SP, Iqbal MP.High prevalence of vitamin D deficiency and insufficiency in a low income peri-urban community in Karachi.J Pak Med Assoc, 2015. 65(9):946-949.

16. QureshiAZ, Zia Z, Gitay MN, Khan MU, Khan MS.Attitudeof future healthcare provider towards vitamin D significance in relation to sunlight exposure.Saudi Pharm J, 2015. 23(5):523-527.

17. KhushdilA, Ullah S, Ali S, Khan I, Awan T.HYPOVITAMINOSIS D IN HEALTHY STUDENTS OF A MEDICAL COLLEGE. Khyber Medical University Journal. 2016,8(4).

18. Nadeem S, Munim TF, Hussain HF,Hussain DF. Determinants of Vitamin D deficiency in asymptomatic healthy young medical students.Pak.J. Med.Sci., 2018. 34(5):1248.

19. RoomiMA, Farooq A, Ullah E, Lone KP. Hypovitaminosis D and its association with lifestyle factors.Pak.J. Med.Sci. 2015,31(5):1236.

20. Mahmood K, Akhtar ST, Talib A, Haider I. Vitamin-D status in a population of healthy adults in Pakistan. Methodology, 2007.Mahmood K, Akhtar ST, Talib A,Haider I. Vitamin-D status in a Population of Healthy Adults in Pakistan. Pak. J. Med. Sci. 2009, 25(4):545-550.

21. Kazi N, Bhurgari AN, Shah AA, Kazi S.25-hydroxyvitamin D3 deficiency in healthy adult men attending Isra University Hospital.Pak. J. Physiol. 2015. 11(2):14-6.

22. Iqbal R, Jafri L, Haroon A, Habib A. Illuminating the dark side-vitamin D status in different localities of Karachi. JCPSP: Journal of the College of Physicians and Surgeons-Pakistan. 2013;23(8):604.

23. Khan AH, Iqbal R, Naureen G, Dar FJ, Ahmed FN. Prevalence of vitamin D deficiency and its correlates: results of a community-based study conducted in Karachi, Pakistan.Arch. Osteoporos. 2012,7(1-2):275-282.

24. HassanS, Muzammil SM, Jafri L, Khan AH.An audit of clinical laboratory data of $25[\mathrm{OH}] \mathrm{D}$ at Aga Khan University as reflecting vitamin D deficiency in Pakistan.J. Pak. Med. Assoc. 2015. 65(11):1247-1250.

25. Riaz H, Finlayson AE, Bashir S, Hussain S, Mahmood S, Malik F, Godman B.Prevalence of Vitamin D deficiency in Pakistan and implications for the future.Expert RevClin. Pharmacol. 2016,9(2):329-338. 
26. WintermeyerE, Ihle C, Ehnert S, Stöckle U, Ochs G, de Zwart P, Flesch I, Bahrs C, Nussler A.Crucial role of vitamin D in the musculoskeletal system.Nutrients, 2016. 8(6):319.

27. Gendelman O, Itzhaki D, Makarov S, Bennun M, Amital H.A randomized double-blind placebo-controlled study adding high dose vitamin $\mathrm{D}$ to analgesic regimens in patients with musculoskeletal pain.Lupus. 2015,24(4-5):483-489.

28. Yilmaz R, Salli A, Cingoz HT, Kucuksen S, Ugurlu H.Efficacy of vitamin D replacement therapy on patients with chronic nonspecific widespread musculoskeletal pain with vitamin D deficiency. Int.J.Rheum.Dis. 2016,19(12):1255-1262.

29. Iqbal Y, Hanif A, Iqbal M, ul Haq A.Prevalence of inadequate level of vitamin D in patients presenting with musculoskeletal pain in Swat region.Journal of Saidu Medical College. 2018,7(1).

30. Achakzai H, Shah H, Zahid SB, Zuhaid M.Hypovitaminosis-D: Frequency and association of clinical disease with biochemical levels in adult patients of RMI Medical OPD.Pak.J.Med.Sci. 2016,32(2):394.

31. Bhatty SA, Shaikh NA, Irfan M, Kashif SM, Vaswani AS, Sumbhai A, Gunpat J.Vitamin D deficiency in fibromyalgia.J. Pak. Med. Assoc. 2010,60(11):949.

32. Khan RR, Yahya KM, Saqib A.Frequency of vitamin D deficiency in patients with fatigue.JUMDC.2014,5(1):26-31.

33. Dar FJ, Iqbal R, Ghani F, Siddiqui I, Khan AHBone health status of premenopausal healthy adult females in Pakistani females.Archives of osteoporosis. 2012,7(1-2):93-99.

34. LoweNM, Ellahi B, Bano Q, Bangash SA, Mitra SR, Zaman M.Dietary calcium intake, vitamin D status, and bone health in postmenopausal women in rural Pakistan.J Health Popul Nutr, 2011. 29(5):465.

35. Khan AH, Naureen G, Iqbal R, Dar FJ.Assessing the effect of dietary calcium intake and 25 OHD status on bone turnover in women in Pakistan.Arch osteoporos. 2013,8(1-2):151.

36. Naveed S, Hameed A, Siddiqui HA, Sharif N, Urooj A.Survey on Prevalence of Vitamin D as Well as Calcium Deficiency Plus Awareness about Osteopenia and Osteoporosis in Females.J Bioequiv Availab. 2016,8:175-178.

37. SaqibMA, Rafique I, Hayder I, Irshad R, Bashir S, Ullah R, Awan NJ.Comparison of vitamin D levels with bone density, calcium, phosphate and alkaline phosphatase - an insight from major cities of Pakistan.J. Pak. Med. Assoc. 2018,68(4):543-547.

38. Pinto JP, Goergen J, Muniz FW, Haas AN.Vitamin D levels and risk for periodontal disease: A systematic review.J Periodontal Res. 2018,53(3):298-305.

39. Khan FR, Ahmad T, Hussain R, Bhutta ZA.Vitamin D status and periodontal disease among pregnant and non-pregnant women in an underdeveloped district of Pakistan.J Int Soc Prev Community Dent.2016,6(3):234.

40. Khan FR, Ahmad T, Hussain R, Bhutta ZA.A randomized controlled trial of oral vitamin D supplementation in pregnancy to improve maternal periodontal health and birth weight.Int $\mathrm{J}$ Dent Oral Health. 2016,8(6): p. 657.

41. Elsori DH, Hammoud MS. Vitamin D deficiency in mothers, neonates and children.J Steroid Biochem Mol Biol. 2018,175:195-199.

42. Hossain N, Khanani R, Hussain-Kanani F, Shah T, Arif S, Pal LHigh prevalence of vitamin D deficiency in Pakistani mothers and their newborns.Obstet Gynecol Int J. 2011,112(3):229-233.

43.Mustafa G, Asadi MA, Iqbal I, Bashir N.Low vitamin D status in nursing Pakistani mothers in an environment of ample sunshine: a cross-sectional study.BMC pregnancy childbirth. 2018,18(1):426. 
44. Muhammad WA, Rai MA, Saba NK.Vitamin D Deficiency Among Healthy Infants.Journal of Rawalpindi Medical College(JRMC). 2014,18(1):52-54.

45. Anwar S, Iqbal MP, Azam I, Habib A, Bhutta S, Soofi SB, Bhutta ZA.Urban and rural comparison of vitamin D status in Pakistani pregnant women and neonates.Journal of Obstetrics and Gynaecology. 2016,36(3):318-323.

46. Riaz M, Shaikh F, Fawwad A, Hakeem R, Shera AS, Hitman GA, Bhowmik B, do Vale Moreira NC, Basit A, Hussain A., Maternal Nutrition during Early Pregnancy and Cardiometabolic Status of Neonates at Birth.J Diabetes Res. 2018, Article ID 7382946, 8 pages. https://doi.org/10.1155/2018/7382946.

47. Haider N, Nagi AG, Khan KM. Frequency of nutritional rickets in children admitted with severe pneumonia.J Pak Med Assoc. 2010,60(9):729.

48. Shah TH, Hassan M, Siddiqui TS.Subclinicalrickets.Pak J Med Sci, 2014. 30(4):854.

49. Shah TH, Hassan M, Siddiqui TS.Subclinical Nutritional Rickets Among Adolescents in Kaghan Valley.J Coll Physicians Surg Pak. 2014,24(9):663-5.

50. Saleem J, Zakar R, Zakar MZ, Belay M, Rowe M, Timms PM, Scragg R, Martineau AR.High-dose vitamin D3 in the treatment of severe acute malnutrition: a multicenter double-blind randomized controlled trial.Am J Clin Nutr. 2018. 107(5):725-733.

51. Giustina A, Bilezikian JP (eds): Vitamin D and Diabetes Mellitus. Vitamin D in Clinical Medicine. Front Horm Res. Basel, Karger, 2018, 50,161-176. doi: 10.1159/000486083

52. BerridgeMJ.Vitamin D deficiency and diabetes.Biochem J. 2017. 474(8):1321-1332.

53. Bashir F, Khan ZU, Qureshi S, Seetlani NK, Sheikh Z., Prevalence of hypovitaminosis D in Type 2 diabetes mellitus and its relationship with glycemic control.J Liaquat Uni Med Health Sci, 2016. 15(02):8388.

54. Javed R and Ghafoor F.A Review of Vitamin D in Pakistani Population. Approved and Indexed by: Pakistan Medical \& Dental Council Higher Education Commission \& EBSCO, ABC Certified,Ophthalmologyupdate. 2016,14(4):189-193.

55. SaleemS, Siddiqui A, Iqbal Z.Vitamin D Deficiency in Patients of Type 2 Diabetes.PJMHS.2017,11(4):1324-1326.

56. Magsi MA, Ijaz A, Maryam A, Yousaf S, Sana F.Vitamin D status and diabetes mellitus.The Professional Med J. 2014,21(03):445-449.

57. Khan AU, Khan MZ, Nadeem M, Bangash RY, Fakhr A.Status of glycemic control in patients of type 2 diabetes mellitus.Pakistan Armed Forces Medical Journal. 2013, 63(2):275-278.

58. IqbalK, Islam N, Mehboobali N, Asghar A, Iqbal MP. Association of vitamin D deficiency with poor glycaemic control in diabetic patients.J Pak Med Assoc. 2016,66(12):1562-1565.

59. RandhawaFA, Mustafa S, Khan DM, Hamid S.Effect of Vitamin D supplementation on reduction in levels of HbA1 in patients recently diagnosed with type 2 Diabetes Mellitus having asymptomatic Vitamin D deficiency.Pak J Med Sci. 2017,33(4):881.

60. Jiang X, Peng M, Chen S, Wu S, Zhang W. Vitamin D deficiency is associated with dyslipidemia: a cross-sectional study in 3,788 subjects.Current medical research and opinion. 2019,35(6):1059-63.

61. Bashir F, Khan ZU, Seetlani NK, Sheikh Z.Pattern of dyslipidaemia and its association with hypovitaminosis D in type 2 diabetes mellitus.J Ayub Med Coll Abbottabad. 2017,29(4):604-609.

62. IqbalK, Islam N, Azam I, Mehboobali N, Iqbal MP. Lack of association of statin use with Vitamin D levels in a hospital based population of type 2 diabetes mellitus patients.Pak J Med Sci, 2018. 34(1):204-208. 
63. Joergensen C, Hovind P, Schmedes A, Parving HH, Rossing P.Vitamin D levels, microvascular complications, and mortality in type 1 diabetes.Diabetescare, 2011. 34(5):1081-1085.

64. Herrmann M, Sullivan DR, Veillard AS, McCorquodale T, Straub IR, Scott R, Laakso M, Topliss D, Jenkins AJ, Blankenberg S, Burton A.Serum 25-hydroxyvitamin D: a predictor of macrovascular and microvascular complications in patients with type 2 diabetes.Diabetes Care. 2015,38(3):521-528.

65. Qu GB, Wang LL, Tang X, Wu W, Sun YH.The association between vitamin D level and diabetic peripheral neuropathy in patients with type 2 diabetes mellitus: An update systematic review and metaanalysis.J Clin Transl Endocrinol. 2017,9:25-31.

66. Khan F, Usman R, Zafar S, Wadud S.Vitamin D deficiency in patients with diabetic retinopathy.J Postgrad Med Inst. (Peshawar-Pakistan). 2017,31(2): 196-8.

67. Pilz S, Verheyen N, Grubler MR, Tomaschitz A, Marz W. Vitamin D and cardiovascular disease prevention.Nat Rev Cardiol, 2016. 13(7):404-17.

68. Simpson RU, Hershey SH, Nibbelink KA.Characterization of heart size and blood pressure in the vitamin D receptor knockout mouse.J Steroid Biochem Mol Biol. 2007. 103(3-5):521-524.

69. Papandreou D, Hamid ZT. The role of vitamin D in diabetes and cardiovascular disease: an updated review of the literature.Disease markers, 2015. 2015, Article ID 580474, 1-15.

70. Mozos I, Marginean O.Links between vitamin D deficiency and cardiovascular diseases.Biomed Res Int. 2015. 2015, Article ID 109275, 1-12.

71. Grant WB.Vitamin D reduces risk of cardiovascular disease. 2019.

72. Sun H, Long SR, Li X, Ge H, Liu X, Wang T, Yu F, Wang Y, Xue Y, Li W. Serum vitamin D deficiency and vitamin $\mathrm{D}$ receptor gene polymorphism are associated with increased risk of cardiovascular disease in a Chinese rural population.Nutrition Research. 2019,61:13-21.

73. Manson JE, Cook NR, Lee IM, Christen W, Bassuk SS, Mora S, Gibson H, Gordon D, Copeland T, D'Agostino D, Friedenberg G. Vitamin D supplements and prevention of cancer and cardiovascular disease.N Engl J Med. 2019,3;380(1):33-44.

74. Mubashir M, Anwar S, Tareen AK, Mehboobali N, Iqbal K, Iqbal MPAssociation of Vitamin D deficiency and VDBP gene polymorphism with the risk of AMI in a Pakistani population.PakJ MedSci. 2017,33(6):13491354 .

75. NazirS, Afzal N, Akram M, Iqbal Z, Raza A, Qayyum M, Naseem AA, Kazmi SA, Tahir F, Afshan K, Jahan SAn investigation into role of circulating concentrations of vitamin D and calcium in the development of hypertension and related cardiovascular diseases. in 19th European Congress of Endocrinology. 2017, May 3 (Vol. 49), BioScientifica.

76. Usman R, Khan F, Khattak M.Correlation of vitamin d with hypertension in patients with cardiometabolic syndrome. J Postgrad Med Inst (Peshawar-Pakistan). 2017,31(3):299-303.

77. Garcia VC, Schuch NJ, Catania AS, Ferreira SR, Martini LAParathyroid hormone has an important role in blood pressure regulation in vitamin D-insufficient individuals.Nutrition. 2013,29(9):1147-1151.

78. He JL, Scragg RK.Vitamin D, parathyroid hormone, and blood pressure in the National Health and Nutrition Examination Surveys.American journal of hypertension. 2011,24(8):911-917.

79. Majid H, Khan AH, Moatter T Moatter. R990G polymorphism of calcium sensing receptor gene is associated with high parathyroid hormone levels in subjects with vitamin D deficiency: a cross-sectional study.BioMed research international. 2015,2015,Article ID 407159, 1-6. 
80. Baggerly CA, Cuomo RE, French CB, Garland CF, Gorham ED, Grant WB, Heaney RP, Holick MF, Hollis BW, McDonnell SL, Pittaway M. Sunlight and vitamin D: necessary for public health.J Am Coll Nutr. 2015,34(4):359-365.

81. Garland CF, Gorham ED.Dose-response of serum 25-hydroxyvitamin D in association with risk of colorectal cancer: a meta-analysis.J Steroid Biochem Mol Biol. 2017,168:1-8.

82. Grant WB. Roles of solar UVB and vitamin D in reducing cancer risk and increasing survival.Anticancer Res. 2016,36(3): 1357-1370.

83. Menhas R, Umer S.Breast Cancer among Pakistani Women.Iran J Public Health. 2015,44(4):586-587.

84. Begum N. Breast Cancer in Pakistan: A Looming Epidemic. JCPSP. 2018, 28(2):87-88.

85. Shaukat N, Jaleel F, Moosa FA, Qureshi NA.Association between vitamin D deficiency and breast cancer. Pak J Med Sci. 2017,33(3):645.

86. Younus A, Faiz M, Yasmeen A.Serum Vitamin D in women with pre and post-menopausal newly diagnosed breast cancer in Pakistan.J Food Nutri Res. 2016,4:828-833.

87. Imtiaz S, Siddiqui N, Raza SA, Loya A, Muhammad A.Vitamin D deficiency in newly diagnosed breast cancer patients.Indian J Endocrinol Metab.2012,16(3):409-13.

88. Imtiaz S, Siddiqui N.Vitamin-D status at breast cancer diagnosis: correlation with social and environmental factors and dietry intake.J Ayub Med Coll Abbottabad. 2014,26(2):186-190.

89. Shamsi U, Khan S, Usman S, Soomro S, Azam IA multicenter matched case control study of breast cancer risk factors among women in Karachi, Pakistan.Asian Pac J Cancer Prev. 2013,14(1):183-188.

90. Qureshi SA, Udani SK, Zehra M, Batool T, Ghani F, Azmi MB.A Cross-sectional Study: Bone Markers in Different Body Mass Index Groups of Newly Diagnosed Breast Cancer Females in Karachi, Pakistan.Int Arch BioMed Clin Res. 2018,4(1):141-145.

91. SARDAR NASIR HUSSAIN KHOSA KM, AHMAD K.Vitamin D Deficiency-A Risk Factor for Breast Cancer.P J M H S, 11(3):992-994

92. Parveen S, Zeeshan R, Sultan S, Irfan SMSerum 25-hydroxyvitamin D Insufficiency in B-Chronic Lymphoid Leukemia at the Time of Disease Presentation in Pakistan.Asian Pac J Cancer Prev. 2015, 16(14):59835986 .

93. Naz A, Qureshi RN, Shamsi TS, Mahboob T.Vitamin D levels in patients of acute leukemia before and after remission-induction therapy.Pak J Med Sci. 2013,29(1):10.

94. Grzybowski A, Pietrzak K. From patient to discoverer. Niels Ryberg Finsen (1860-1904) the founder of phototherapy in dermatology.Clin Dermatol. 2012,30(4):451-455.

95. Rode AK, Kongsbak M, Hansen MM, Lopez DV, Levring TB, Woetmann A, Odum N, Bonefeld CM, Geisler C. Vitamin D counteracts Mycobacterium tuberculosis-induced cathelicidin downregulation in dendritic cells and allows Th1 differentiation and IFN $\gamma$ secretion.Front Immunol. 2017,8:656.

96. Selvaraj P. Vitamin D, vitamin D receptor, and cathelicidin in the treatment of tuberculosis.Vitam Horm. 2011, 86:307-325.

97. Zhan Y, Jiang L.Status of vitamin D, antimicrobial peptide cathelicidin and T helper-associated cytokines in patients with diabetes mellitus and pulmonary tuberculosis.Exp Ther Med. 2015,9(1):11-16.

98. Talat N, Perry S, Parsonnet J, Dawood G, Hussain R.Vitamin D deficiency and tuberculosis progression.EmergInfect Dis. 2010,16(5):853-5.

99. Pareek M, Innes J, Sridhar S, Grass L, Connell D, Woltmann G, Wiselka M, Martineau AR, Kon OM, Dedicoat M, Lalvani A.Vitamin D deficiency and TB disease phenotype.Thorax. 2015,70(12):1171-1180. 
100. Huang SJ, Wang XH, Liu ZD, Cao WL, Han Y, Ma AG, Xu SF. Vitamin D deficiency and the risk of tuberculosis: a meta-analysis.Drug Des Devel Ther. 2017,11:91-102.

101. Memon A, Raqeeb A, Humaira M, Khoharo HKVitamin D3 in Newly Diagnosed Pulmonary Tuberculosis Patients: A Comparative Case Control Study.J Liaquat Uni Med Health Sci. 2016;15(01):16-20. (0 Hemoglobin (g/dl), 2016. 39:34-8.

102. Junaid K, Rehman A, Jolliffe DA, Saeed T, Wood K, Martineau AR. Vitamin D deficiency associates with susceptibility to tuberculosis in Pakistan, but polymorphisms in VDR, DBP and CYP2R1 do not.BMC pulmonary medicine. 2016,16(1):73.

103. Iftikhar R, Kamran SM, Qadir A, Haider E, Bin Usman H.Vitamin D deficiency in patients with tuberculosis.J Coll Physicians Surg Pak. 2013,23(10):780-3.

104. Mehr MT, Khan H, Iman NU.How frequently are people with newly diagnosed pulmonary tuberculosis deficient in vitamin D levels in Khyber Pakhtunkhwa: a pilot study project.J Postgrad Med Inst.2016; 30(3): 235-9.

105. Jamali AA, Lighari JH, Shaikh S, Jamali GM, Tanwani BM, Channa MA, Jamali AA, Suhail MA. Vitamin D: Level of Vitamin D3 in AFB Positive PTB Patients in Initial Diagnostic Phase.J Tuberc Res. 2018,6(04):251-269.

106. Azam F, Shaheen A, Arshad R.Frequency of hypovitaminosis D and its associated risk factors in newly diagnosed pulmonary tuberculosis patients.Pak JMed Sci. 2016,32(2):480-484.

107. Mashhadi SF, ur Rahman M, Azam N, Hashim R, Khan A, Fawad AAssociation of vitamin d deficiency with tuberculosis in adult patients reporting to a tertiary care hospital of Rawalpindi.Pak Armed Forces Med J. 2014; 64 (3):479-483.

108. Iqbal NT, Fatima SS, Hussain R, Rao NA, Virji N, Jamil B, Irfan M.Interplay of chemo attractant peptides (cathelicidin and chemerin) with vitamin-D in patients with pulmonary tuberculosis.Br J Med Med Res. 2015,7(7):611-622.

109. Salahuddin N, Ali F, Hasan Z, Rao N, Aqeel M, Mahmood F.Vitamin D accelerates clinical recovery from tuberculosis: results of the SUCCINCT Study [Supplementary Cholecalciferol in recovery from tuberculosis]. A randomized, placebo-controlled, clinical trial of vitamin D supplementation in patients with pulmonary tuberculosis'.BMC Infect Dis. 2013,13(1):22.

110. Azam F, Shaheen A, Zuberi FF.Comparative effect of ATT alone and in combination with Vitamin D on physiological and laboratory parameters in pulmonary TB.JDUHS, 2015. 9(3).

111. Afzal A, Rathore R, Butt NF, Randhawa FAEfficacy of Vitamin D supplementation in achieving an early sputum conversion in smear positive Pulmonary Tuberculosis.Pak J Med Sci. 2018,34(4):849-854.

112. Strzelak A, Komorowska-Piotrowska A, Ziołkowski J. CXCL10/IP-10 as a new biomarker for Mycobacterium tuberculosis infection. Polski merkuriusz lekarski: organ Polskiego Towarzystwa Lekarskiego. 2012,33(198):342-345.

113. Hasan Z, Salahuddin N, Rao N, Aqeel M, Mahmood F, Ali F, Ashraf M, Rahman F, Mahmood S, Islam M, Dildar B.Change in serum CXCL10 levels during anti-tuberculosis treatment depends on vitamin D status.Int J Tuberc Lung Dis.2014, 18(4):466-469.

114. Valdivielso JM, Fernandez EVitamin D receptor polymorphisms and diseases.Clinica Chimica Acta. 2006,371(1-2):1-12.

115. Alizadeh S, Djafarian K, Alizadeh H, Mohseni R, Shab-Bidar S.Common Variants of Vitamin D Receptor Gene Polymorphisms and Susceptibility to Coronary Artery Disease:A Systematic Review and Meta-Analysis.Lifestyle Genom. 2017,10(1-2):9-18. 
116. Wang TJ, Zhang F, Richards JB, Kestenbaum B, Van Meurs JB, Berry D, Kiel DP, Streeten EA, Ohlsson C, Koller DL, Peltonen LCommon genetic determinants of vitamin D insufficiency: a genome-wide association study.The Lancet. 2010,376(9736):180-188.

117. Bikle DD. Vitamin D metabolism, mechanism of action, and clinical applications. Chemistry \& biology, 2014. 21(3):319-329.

118. Campbell FC, Xu H, El-Tanani M, Crowe P, Bingham V. The yin and yang of vitamin D receptor (VDR) signaling in neoplastic progression: operational networks and tissue-specific growth control. Biochem Pharmacol. 2010,79(1):1-9.

119. Sakharkar P.Vitamin D Receptor (VDR) Gene Polymorphism: Implications on Non-Bone Diseases.J Basic Clin Pharma. 2017;8:S06-S10.

120. Triantos C, Aggeletopoulou I, Kalafateli M, Spantidea PI, Vourli G, Diamantopoulou G, Tapratzi D, Michalaki M, Manolakopoulos S, Gogos C, Kyriazopoulou V.Prognostic significance of vitamin D receptor (VDR) gene polymorphisms in liver cirrhosis. Sci Rep. 2018. 8(1):14065.

121. Zaki M, Kamal S, Basha WA, Youness E, Ezzat W, El-Bassyouni H, Amr K.Association of vitamin $\mathrm{D}$ receptor gene polymorphism (VDR) with vitamin D deficiency, metabolic and inflammatory markers in Egyptian obese women. Genes Dis. 2017,4(3):176-182.

122. Haddad S.Vitamin-D receptor (VDR) gene polymorphisms (Taq-I \& Apa-I) in Syrian healthy population. Meta gene, 2014. 2:646-650.

123. Ogunkolade BW, Boucher BJ, Prahl JM, Bustin SA, Burrin JM, Noonan K, North BV, Mannan N, McDermott MF, DeLuca HF, Hitman GA.Vitamin D receptor (VDR) mRNA and VDR protein levels in relation to vitamin D status, insulin secretory capacity, and VDR genotype in Bangladeshi Asians. Diabetes. 2002,51(7):2294-2300.

124. Mukhtar M, Batool A, Wajid A, Qayyum I.Vitamin D Receptor Gene Polymorphisms Influence T1D Susceptibility among Pakistanis.Int J Genomics. 2017;2017:4171254.doi: 10.1155/2017/4171254.

125. Nasreen M, Lone KP, Khaliq S, Khaliq S.Serum vitamin D levels and gene polymorphisms (Fok1 and Apa1) in children with type I diabetes and healthy controls. JPMA, 2016. 66(1215).

126. Younus A, Faiz M, Yasmeen A.Association of Vitamin D Receptor FokI and TaqI Gene Polymorphisms in Pakistani Women with 25 (OH) D Levels.J Food Nutr Res. 2017,5(7):475-480.

127. Speeckaert M, Huang G, Delanghe JR, Taes YE. Biological and clinical aspects of the vitamin D binding protein (Gc-globulin) and its polymorphism. Clinica chimica acta. 2006,372(1-2): 33-42.

128. Iqbal K, Islam N, Azam I, Asghar A, Mehboobali N, Iqbal MP. Association of Vitamin D binding protein polymorphism with risk of type 2 diabetes mellitus in a Pakistani urban population: A case control study.J Pak Med Assoc. 2017,67(11):1658-1663.

129. Kakarala M, Rozek L, Cote M, Liyanage S, Brenner DE.Breast cancer histology and receptor status characterization in Asian Indian and Pakistani women in the US-a SEER analysis. BMC cancer. 2010,10(1):191.

130. Iqbal MU, Khan TA. Association between vitamin D receptor (Cdx2, Fok1, Bsm1, Apa1, Bgl1, Taq1, and Poly (A)) gene polymorphism and breast cancer: a systematic review and meta-analysis. Tumor Biology. 2017,39(10):1010428317731280.

131. Khan TA, Maqbool SA. Vitamin D receptor Cdx-2 polymorphism and premenopausal breast cancer risk in southern Pakistani patients. PloS one, 2015. 10(3):e0122657.

132. Iqbal MU, Maqbool SA, Khan TA. Association of low penetrance vitamin D receptor Tru 9I (rs757343) gene polymorphism with risk of premenopausal breast cancer.J Int Med Res. 2018,46(5):1801-1814. 
133. Rashid MU, Muzaffar M, Khan FA, Kabisch M, Muhammad N, Faiz S, Loya A, Hamann U. Association between the BsmI Polymorphism in the Vitamin D receptor gene and breast cancer risk: Results from a Pakistani case-control study. PLoS One. 2015,10(10):e0141562.

134. Batieha, A., Khader, Y., Jaddou, H., Hyassat, D., Batieha, Z., Khateeb, M., .. \& \& Ajlouni, K. (2011). Vitamin D status in Jordan: dress style and gender discrepancies. Annals of Nutrition and Metabolism , 58 (1), 10-18.

135. Al Attia, H. M., \& Ibrahim, M. A. (2012). The high prevalence of vitamin D inadequacy and dress style of women in the sunny UAE. Archives of osteoporosis, 7(1-2), 307-310.

136. Siegel-Itzkovich, J. (2001). Ultra-Orthodox Jewish women at risk of vitamin D deficiency. BMJ: British Medical Journal, 323 (7303), 10.

Table 1: Studies indicating vitamin D status in the healthy individuals of Pakistan

\begin{tabular}{lll}
\hline Total number of individuals & Male and Female $(\%)$ & Number of individuals with vitamin D levels $(<30 \mathrm{ng} / \mathrm{m}$ \\
\hline 300 & $65 \%$ and $35 \%$ & $272(84 \%)$ \\
858 & $41 \%$ and $59 \%$ & $768(89.5 \%)$ \\
500 & $29 \%$ and $71 \%$ & $438(87.6 \%)$ \\
104 & $37.5 \%$ and $62.5 \%$ & $99(95.2 \%)$ \\
191 & $86 \%$ and $14 \%$ & $170(89.1 \%)$ \\
88 & $57 \%$ and $43 \%$ & $87(98.86 \%)$ \\
244 & $21 \%$ and $79 \%$ & $186(76.2 \%)$ \\
180 & $100 \%$ male & $160(88.8 \%)$ \\
4788 & $29 \%$ and $71 \%$ & $3562(74.4 \%)$ \\
305 & $100 \%$ female & $275(90.1 \%)$ \\
60937 & $31 \%$ and $69 \%$ & $37233(61.1 \%)$ \\
4830 & $33 \%$ and $67 \%$ & $4091(84.7 \%)$ \\
Total individuals $=73325$ & Overall male $31 \%$ and female $69 \%$ & Overall $=47341(64.6 \%)$ \\
\hline
\end{tabular}

Table 2: Vitamin D deficiency in different health conditions in Pakistani population

\begin{tabular}{lll}
\hline Health conditions & No. of studies & References \\
\hline Musculoskeletal, bone and Periodontal health & 09 studies & $29,30,32-38$ \\
Nursing mothers and children & 11 studies & $4,42-59$ \\
Diabetes mellitus & 08 studies & $55-58,60-63,66$ \\
Cardiovascular disorders & 07 studies & $53,74-79$ \\
Cancer & 09 studies & $85-93$ \\
Tuberculosis & 16 studies & $98-113$ \\
Genetic studies & 10 studies & $124-133$ \\
\hline
\end{tabular}

